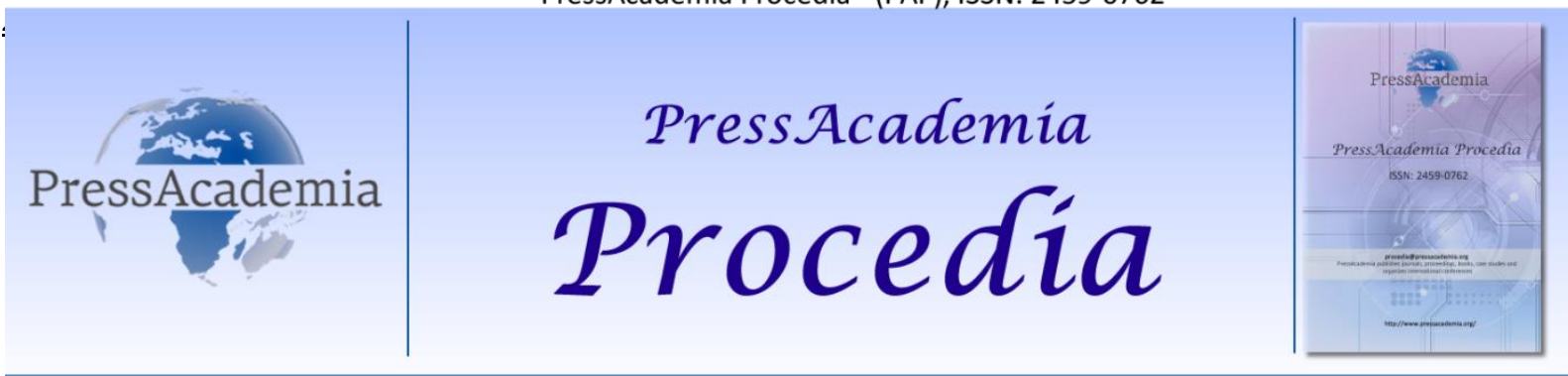

2nd World Conference on Technology, Innovation and Entrepreneurship

May 12- 14, 2017, Istanbul, Turkey. Edited by Sefer Şener

\title{
THE ROLE OF INSTITUTIONS WITHIN NATIONAL AND REGIONAL TECHNOLOGIC INNOVATIONS IN THE USA AND GERMANY
}

\author{
DOI: 10.17261/Pressacademia.2017.534
}

PAP-WCTIE-V.4-2017(26)-p.191-198

\section{Hulya Derya, Elif Kaya}

Kilis 7 Aralik University. hulyaderya11@gmail.com

Kilis 7 Aralik University. elifk.7@hotmail.com

\begin{abstract}
If we a little bit elaborating Schumpeter model of technological innovation (invention $\rightarrow$ innovation $\rightarrow$ diffusion), we can confirm that every stage of innovation process is frankly interconnected. With this judgement, it is also seen that socio-economic institutions are quite influential in the emergence of technological innovation. The main purpose of this paper is to figure out why countries show different level of success; moreover, what kind of effects national education, finance and science have on national and regional technological advances. Furthermore, the role of radical and process innovation is examined in respect of national technological advance and institutional innovations. In this regard, two countries are contrast and compare, namely the USA and Germany.
\end{abstract}

Keywords: Schumpeter, radical innovation, process innovation JEL Codes: 014, O31, 033

\section{INTRODUCTION}

In economics science, institutional transformation has been significant under the evolutionary developmental biology models that define humanity's historical development gradually. Breaks of institutions can be regarded as inevitable for economic advancements. Until Schumpeter put forward the importance of research and development, new technologies have been taken as a production of economic activities. However, it is also wrong that new technologies are merely on the research and development scope as it can be emerged in every stage of production chain. Besides technological and economic components, socio-economic institutions are being significant as impact factor too. Furthermore, social limits conditions and institutions influence on composing of new technologies indirectly. When countries are assessed in terms of composing of new technologies, the type of country's technological innovations are appeared in accordance with social and institutional limits conditions. It is expected that the institutions are being in flexible structure and leading radical changes via creative destruction. Germany has succeeded process innovations since 1980s. For the United States of America, it can be claimed that she is a pioneer of radical innovations. In this paper, it is provided an insight in the ability of transformations and breaks in the economics of both Germany and the United States. The precautions, that are taken after 2000, about institutions are not considered in this work because it seems more important to see the roots of lasting problems for years than the slowly changing process. The main aim of the paper is indeed seeking answers to the questions about how different the institutional flexibility within Germany and the USA, and the obstacles against it in these two.

\section{TECHNOLOGICAL INNOVATION}

Innovation or technical progress is defined as a change of production function. The term of innovation is a Latin word and primarily refers to renewal (i.e. products, firms type, structure type, methods, organisations, etc.) Innovations consists of two parts; a. radical innovations, b. process innovations. On the one hand, process innovation is a high valued improvement strategies emerged in the duration between entrepreneur and the actors taking place in innovation process. Entrepreneur could improve the goods and services as a result of the interaction between distributor and customer (Ritter, 1993:137). 
Radical innovation, on the other hand, is the quantum leap in the development of new products, product manufacturing methods or organizational forms. With them, new markets and customers are gained. ${ }^{1}$ In the models of neoclassical economics, innovations happened by chance and it has an external character. Schumpeter, however, comprehend the significance of innovations and he announces investor a leading player of innovations in his well-known work "Theorie der Wirtschaftlichen produktionsmittelvorrat neu Kombiniert" (Schumpeter, 1912). In this way, he individualized innovation movement.

Investors present new products to markets. This will lead economy to a dynamic improvement process with the support of creative destruction. In 1942, Schumpeter put the role of research and developments in big companies into his theory (Schatzl, 1996:10). For Schumpeter, improvement process of technical advancement is realised in three main stages, namely, invention, innovation, diffusion, respectively.

INVENTION $\rightarrow \quad$ INNOVATION $\rightarrow \quad$ DIFUSION

Source: Backhaus,1999:8

Here, invention refers to find or create something totally new, something entirely unknown before. In the stage two, with innovation, the invention is accepted for first time and achieve success. Then, in the last stage, there is a spread all over. Thus, Schumpeter's creative destruction demolish the old order and build the new (Schatzl, 1996:110).

If newly established firms with new technology could not be successful immediately, they are blocked from the market, so economic advancement is damaged from it. Moreover, the pressure of being creative coming from newly established firms towards the current ones is stopped since current firms tries to keep their routine. It is self-evident fact that new firms provide the essential innovations throughout the history of economics. Additionally, there are enough evidence to accept this assumption is also true for radical innovations. ${ }^{2}$ Current firms generally find it difficult to marketing radical innovations. ${ }^{3}$ If innovations get grounding in scientific knowledge day by day, then new trouble has occurred because scientific invention should be harmonised throughout the economy in the first place. Here the bridge between science and economy is built mostly by new companies under the rule of scientist. ${ }^{4}$ Without evolution, innovation cannot survive. In Schumpeter's theory, the stages of technological innovation process have not been connected each other and there is no feedback mechanism. Information flow is only one way. In this point, it is essential to approach his model critically because the root of innovation does not rely merely on science and research but must conceive the needs of distributors and customers. The perception that innovations could come with investments all the time should be corrected.

Figure 1: Model Based on Interaction

\section{RESEARCH}

$\downarrow \uparrow$

\section{KNOWLEDGE}

\section{$\uparrow \uparrow \uparrow$}

\section{POTENTIAL MARKET $\leftrightarrow$ INVENTION $\leftrightarrow$ TEST STAGE $\leftrightarrow$ PRODUCTION $\leftrightarrow$ DIFUSION}

Source: Backhaus,1999:9

Common evolution of evolutionary and innovative firms is the driving force of market economy systems. This entrepreneur composes the core of information society. Evolutionary modernism paradoxically makes it necessary to overcome integration problems. Thus, evolutionary entrepreneurs obligate to do it. Interaction between innovation and evolution also take place in some partial systems of society. If politics, law or science paralyze common evolution of economic base of innovative enterprises, development target could not be reached. Therefore, wave dynamic is eroded, economy is being a dead sea.

\footnotetext{
${ }^{1}$ Cars using higher technology day by day can be considered as an example of a process innovation while invention of computer in last century can be regarded as radical innovation.

${ }^{2}$ We can define innovations as NBIC (Nano, Bio, Info, and Cogno) innovations. Innovations that has radical/destructive nature has shown converging characteristic, that includes different research field knowledge, thus, it requires new kind of specialisation current firms do not have.

${ }^{3}$ Among them, we can tell there are some big companies such as Toyota, Roche, General Motor.

${ }^{4}$ As it is not directly relevant, we cannot detail it here but it should be known that it has been happening in the USA so successfully. It is almost regarded as a mission for a professor to establish a company to apply their findings, especially if they work in physical sciences.
} 


\section{THE OBSTACLES OF INSTITUTIONS FLEXIBILITY}

There are two underlying thoughts behind of the thesis: "breaks are inevitable for improvements". First, institutions should be continuous to provide orientations. Continuity of institutions, on the other hand, are possible with the existence of stabiliser. New institutions have risks as once inventions get into an economy; it needs to be accepted by the society. Secondly, institutions can oppose the ambient conditions since stabilising elements has limited transformation ability. That is why, breaks in institutions are inevitable to adopt changing world conditions. The independence and flexibility which provide breaks to happen in institutions are also determine whether a country has voice into radical or process innovations. This transformation model depends on evolutionary-biological improvement that occurs via bitty breaks. Long-term recessions are stopped by sudden phenomes (Gowdy, 1992:4). From 1980's, this envision having great impact on the transition and progress approach in social science has a highly intuitional convincing since plenty of events throughout the history can be explained in this way (i.e. revolutions).

The new researches about institutional transitions focus on a culture embedded stabilising factor in. Therefore, firstly seek an answer to the question of "what is culture?". (Hermann, 1993:95). Culture is a contemporary reality that is inherited from the past to nowadays. Decisions towards future always depends on that kind of reality in the context of cultural components. Thus, new cultures are not composed for no reason. When the cultural values are detected, it can also be identified their ability to influence on transformations.

Other stabilising factors beyond the institutional breaks are insecurity, investments and interests. Those can be seen as secondary stabilising factors. Culture has two qualities that make itself valuable, namely, culture affect perception, and culture is long-term phenomenon transformed only in long-term. Additionally, these secondary stabilizers play a significant role on to shape transformation as it has an impact on culture. For instance, keeping high insecurity or interests still will largely affect culture's transformation ability. Primarily, in light of the insecurity stabilizer, the knowledge about possibility of action can be seen as follows; 1 . Knowledge can be perfect and certain. 2. Knowledge can be imperfect and certain. 3 . Knowledge can be perfect and uncertain. 4. Knowledge can be imperfect and uncertain. In practice, the last is the most common one we see. Although actors know all behavioural pattern, they do not entirely aware of its content, or see neither all alternatives nor evaluate its costs. Thus, decisions are made in insecure environment. If we assume that, however, people escape from insecure environment, it means safer solvation is preferred (Priddat, 1994:6). Because, in this way, uncertainty is maintained for the costs arising from the form new institutional methods or the costs coming from receiving new information of that. Because of this, it is decided to keep current institutions in its way. It is the same for investments. Individuals invest in their own "institutions". Here, they must obey the rules about jargon, codes, routines, contract, and agreement; and this brings costs together with it. That very costs are specific and high as it is unique for every institution and cannot be transmitted from one to another easily. Each firm create their own jargon, codes, routines etc. In addition to these fixed costs, marginal costs can be added top on them comfortably and cheaply. For a new institution, there are both fixed costs and variable costs. Investors ask if the investment is worth to do since even the gain from current institution is getting lower may be accepted. Investors have the perception of a current institution bring more benefits than a new one.

The last but not the least important one is political interests. The allocation effect occurs from establishing new institute do not evenly distribute to the members. On the one hand, some members rewarded by current institutions would be against to the modifying of the distributional structure. Nevertheless, if they allow to establishment of new institutionalism, there will be a cost as other members who are not rewarded yet will demand their share. On the other hand, even if all members seek a new solution-collective action we named-, there is still a problem. In common level, all members will benefit from the new institutionalism, but in individual level, old institutionalism seems to have more advantages (it is a familiar issue of the game theory). Hence, they will not go for new institutionalism. ${ }^{5}$

Insecurity, investments and interests cannot live by themselves, they are existed because of perception of the observers. Different conceptual models determine the degree of insecurity perception, affect the level of sunk investments, and settle the intensify of various interests. In this context, the culture ready to take risks takes different position than the risk-averse one. Similarly, existing conditions or priorities affect institutions' transformation abilities as the dependence on these conditions and priorities have different kind of weight compare to prisoner's dilemma. Hence, the perception of these stabilizers' cultural dimension is an important factor, so the culture could gain a solid dynamic in cultural transformation in this way. Education system, structure of banking system, governments, law, and individualism closely affect institutions flexibility. Technological innovations are possible to evaluate on a country bases. Those can be geared in a line between liberalism and corporation. Thereunder, under the social and institutional frame, a country's form of technological innovation is taken shape. Germany is a process innovation country whereas the US is the pioneer for radical innovations. Soskice (1997) mentions two groups. From his point of view, in the first group that consists of the US, England, and Ireland

\footnotetext{
${ }^{5}$ Insecurity, investments and interests influence unofficial institutions rather than official ones. A specific interest of an investor culture would lead employees to embrace this culture.
} 
(Anglo-Saxons), radical innovations occur because of their unconstrained structure while in the second one which includes Nederland, Germany, Japan, process innovations are dominant (Soskice, 1997:340-350).

\section{GERMANY'S SITUATION IN TECHNOLOGICAL INNOVATIONS}

Germany, especially after the WWII, has tried to close the gap between itself and the industrialized western countries in terms of space research, nuclear energy and communications technologies. However, this approach became so problematic as knowledge could not integrated into the economy or existed technologies did not allow changes owe to their high costs (Keck, 1993:134-137). Germany tent to compose core industries and chemical-medical cluster. 19 of 25 companies in this sector is established before 1913. Today, these companies are active in manufacturing automotive, electronics industry, making machines and chemical industry. The companies, they were exporters even in 1913, are still producing the biggest share in Germany's exports. After 1970s, Germany get into a recession about innovations (Keck, 1993:134-137).

Why Federal Germany is not working in radical technology as it did in 1970s?

Related questions to the issue can be ordered as follows:

- Is there any absence of the potential to increase knowledge that help to create a new technology?

- Are they focusing on economically worthless knowledge or technology instead?

- Is there any deficiency in acquiring of knowledge?

- Is there any problem to use of knowledge?

It is obvious that big research institutes are not flexible enough, thus they can neither afford the potential needs of the changing society and economy nor provide the research and technology that is transformed to products within the sectors. With the decrease in nuclear energy researches in Germany, especially big research institutions be strict in the structures (Erber, 1998:6-7). Moreover, most of the time it is seen that existing institutions cannot adapt to the rapid changes in conditions as they are not flexible enough. It may not be a result of the shortage of institutionalism, may be a consequence of the institutional lock-in effect. Institutions are generally graded, so it has ability of evolutionary transformation. Eventually, because there is no shocking mainly raised from the institutions there will be no finding its own level again in the economy field. Schumpeter's innovation process that he named as creative destruction means big obliteration as they cannot meet the changing requirements result of the social transformation. Exceptions also confirm that there are rare breaks within the institutions. The research institutions and economy can be related to each other only when they are interconnected (Erber, 1998:7-8). For Schumpeter, energy of the act combines with the knowledge, new notions, creativity, and intelligence here.

An international commission decides that research system in Germany has no ability to adapt to the rapid changes of innovative cycle or conditions accompanied by globalization (Erber, 1998:8-9). German information system is not entirely get into research fields and shows apparent lack of penetrate existing institutions to work to make them more flexible. There are various reasons why institutions are not flexible, such as, labour force employment, education structure, tax rates etc.

Germany, for Soskice, could be categorized into coordinated market economy. During the coordination process, foundations and unions are extremely important. With the liberal glance at it, it might be thought that these framed conditions would restrict investors. However, collective advantages also emerged from this too. Strong economic unions and foundations constitute well advanced regulator structures. Those, on the one hand, work to solve conflicts; on the other hand, try to create standards. German work-relations-system guarantees labour force employment; thus, it encourages the establishment of institutions with fundamental technologic qualifications that are necessary for process innovations ${ }^{6}$ (Soskice, 1997:340).

German education institutes/universities are not attentive to the training of entrepreneurs/investors compare to their American peers. Ability of entrepreneurs/investors are unintentionally dulled within German education system. Potential entrepreneurs/investors get through this system are employees with high standards but as an enterpriser they are impotent. They remain either potentials with high standards or being unsuccessful enterprisers. Therefore, universities and other kind of education institutes are not only a traditional manufacturer of knowledge but practitioner of it too. That is to say, this give them a key position as new combinatorics. ${ }^{7}$ Entrepreneurs/investors abilities gained in the universities are in

\footnotetext{
${ }^{6}$ That kind of establishment may also lead to decrease in flexibility and pace. Establishment or close an institution might be harder, radical innovation would not realise.

${ }^{7} \mathrm{New}$ combinatorics are Schumpeterian investors. According to his point of view, development is coming from combination. Without its existence, every economy inevitably loses its balance and slide into recession because innovation cannot realise by itself. Thereafter, there are ability, desire, and its conditions comes to the stage. At this very point institutions step in. If we consider universities as institutions, we will see that universities have abilities, they desire, and they have facilities so that they could innovate.
} 
the centre of international information society, knowledge-based strategy, and economic development. Conventional education and didactics cannot raise innovator-commentator (entrepreneur) individuals. This, the most active element of economics world is not in compliance with the passive and recessionary education given to children. Otherwise, learning process would be related to academic transmission. Learners' passion for building career contrast to the long and experimental learning system. Having only specialized knowledge is not sufficient; value-oriented key abilities and independent skills are strictly necessary. If not so, invention and benefits from knowledge would be blocked. ${ }^{8}$ (Haga and Röpke, 2007:7-13).

Innovation connotes high risk premium. Whether an innovator takes risk or not is entirely depending on the risk premium. It is under the control of tax legislation in Germany, which raise tax rates from 36.5 per cent to 41.2 per cent from 1975 to 1985 (Neuman, 1985:6-7). German Ministry for Economy (it is named as Ministry for Economic Affairs and Energy since 2013) Science Committee (1985) argued that high tax rates have profound negative effects on entrepreneurship, especially on the innovation tendency of them. For independent firms, high taxes and social expenditures make it harder to be raised in their field because they consider it as working harder and taking much more responsibilities for free" (Wissenschaftliche Beirat Beim Bundeswirtschaftsminiserium, 1985). Moreover, Neuman (1985) emphasized that increase in taxes slow down the innovations. In this context, in the comparison of the USA with Germany, it could be said that taking risks is not a custom in Germany as it is in the USA.

Rise in wages has influence on both technical advances and its type in terms of labour savings (Neuman, 1985:6-7). Some experimental researches confirm it with its findings. For instance, Krelle (1985) finds that increase in the wage-interest relations since 1960 bring capital intensity within Federal Germany. Related to this, it can be stated that the rise in wageinterest relation impacts technical advances type in Germany. The biggest advantage of German financial system is to give loans with fixed interests and long term. In this way, entrepreneurs do not suffer from credit squeeze, furthermore, their risk position becoming lower than it does in other countries. Because German innovation system is export-oriented and has specific institutional structure, it encourages high-valued product improvement strategies. Process innovations emerges in the long-term relationship between companies and actors. For product innovation, it can be said that it is an increasing improvement in already existed products (Röpke, 2002:20-30).

Another important issue is the stimulation provided by universities and public research institutions via private sector. In Germany, donations are hardly seen whereas in the USA, donations play a key role for subsidise. Many donators in the USA consist of graduates who transmit their knowledge into business as new combinations. Many of those are young entrepreneurs who come from scientific society with the knowledge of recent data and technology. That donation revenue undertakes a mission to not to separate economy from science. Innovative establishers from research centres are being intersection point between science and economy. However, political management of this intersection point is quite hard. Global competition conditions show us Germany stay behind (Blattel-Mink, 1995:61).

There are so many foreign scientists and students living in there. However, Germany cannot realize the improvement potential they provide as a. components of evolution are neglected b. foreign scientists and students cannot apply what they know or learn. If that kind of policy was implement in the USA, there would be nothing like the Silicon Valley (Haga and Röpke, 2007:17).

Re-organisation and rebuilding of the flexibility of institutions in Germany could be possible only when stiffness and ineffectiveness are eliminated. In this certain point, it is reasonable to keep away from available formula and solutions. Here, it is effective to create a fair competition conditions and to implement an effectiveness-rising-measurements package. Also, providing independence to the actors is necessary for them to reach their productivity. Institutional competition would be encouraged solely once the fair playing rules come down to the ground. Prudential institutions are needed to create an institutional competition ground.

\section{AMERICAN LEADERSHIP IN RADICAL INNOVATIONS}

The USA developed radical-oriented technology policies especially during the WWII and they build a tradition derived from the big military projects. Among them, the Manhattan Project, which is responsible to create atomic bomb, is the most famous one. Later, that military experience has used for civilian goals effectively. While NASA carry out Apollo Project, they benefit from radical-oriented technology policies that almost militarily organised. Because these projects launched by the USA government, there would be no need for stratified perfection. The President of USA always get his techno-politic targets according as Congress support him financially. National security discourse is generally used for convincing the public. As whether the research foundation is used for military purpose of not has not been questioned, military budget is

\footnotetext{
${ }^{8}$ What happens in education system is generally the opposite of that (at least it is in Germany). "Joy of success, openness to innovations and will of taking risk is neglected so far (Frankfurter Institute). Additionally, Peter Glotz observed that in German universities life-time learning is totally unknown, indeed it is just a word for them.
} 
deployed for even civilian purposed technologies. Existence of the American military forces do not only improve communication-informatics technologies but also give support for researches in biotechnical and genetics field to develop biologic weapons.

For climate and environmental researches, it is still benefitted from the database of NASA, American Air and Navy force. Military researches always have potential to use in civil fields. Air Boeing 707, for example, is originally designed to carry atomic bomb. Also, today's internet is invented to provide logistical support for American army. Yet most of them lost its military purpose after this dual-use, but still from photo-cameras to transistors, most of inventions revert to the civil life (Soskice, 1994:340-345).

The new projects such as liquid panel projects, next generation internet projects or cryptography projects, today serve for both military and civil source, thus researches remain in dual-use base. The USA, therefore, give up on to separate its industrial bases into civilian or military. The USA's military strategy in the field of research and technology is relied on industrial base of all the sectors. Today, the perception is partially changed to the opposite direction and it is argued that how to use original civil technology for military purpose. This is seen specifically in civilian computer industry that is developed semiconducting materials (Soskice, 1997:338; Blatter-Milk, 1995:61-65).

Although American techno-policy was rather military-oriented in the past and civil use of this technology is generally neglected even within the dual-use model, today the USA has been much more sensitive about it as it had gone through competition weakness during 1980s. In contrast to the past, the USA does not eager to serve its knowledge about technology to the rest of the world. Concordantly, it has implemented much strict law about patent and licence as well as encouraged the companies use their potential with in the country instead. On the one hand, there are big areas which is called "manufacturing belt" and blanket the cost side of big oceans within the USA' economic core. These areas are famous especially with the automobile industry. On the other hand, there is a place named "electronic highway" in Boston and finally newly build "sun belt" region in the south of the USA, which means sun ladder and represent aviation-space industry.

The USA is the leader of radical technologies. It owes this to the institutions flexibility. Division of labour, education, tax rates and stimulation structure is formed accordingly. American schools and vocational education system is quite disorganised and getting smaller day by day. Here education and research opportunities are formed according to the market demand usually. University professors take positions in the direction of market decisions. Additionally, universities take all burden to make researches that market demand requires. In other respect, competition between education institutions compose very core of the system. Thus, all research facilities run to the processing of high-tech production that is essential for innovation progress, and the progress is backed up by American education system (Soskice, 1997:338).

For Soskice (1997), the USA has a place among the countries having liberal organisations within market economies. Here, companies and especially companies in the export sectors do not get into the institutional settlement like that is in Germany. Foundations do not play an important role in national technological innovations in the USA. This specific generation make it hard to corporate for entrepreneurs due to the strong competition policy (Soskice, 1994: 340-341). In the USA, there is not regulatory structure to put standards on the market or to determine the competitions in a sector; market is not regulated. Labour markets are largely free and unions are relatively weak in this country (Blattel-Mink, 1995:61). This pave a way to occur flexible labour market with no effort just as it is needed. ${ }^{9}$

The American government role is also crucial for radical innovations in the USA. The state emerges as a factor that create employment in the military and space researches (i.e. Silicon Valley). The USA's research and development spending is quite high by 3 percent of its budget. Within this framework, it is obvious that the United States is built for radical innovations. Conclusively, for the USA, keystones of being a leader for radical innovations are flexible institutions, universities, and researches supported by the government, which are embedded in liberal market economy (Musiolik, 2001:21-22).

\section{COMPARISION GERMANY WITH THE UNITED STATES ABOUT INNOVATIONS}

Because institutions in Germany is not flexible enough, new entrepreneurs come from research institutions cannot build a structural linkage between science and economy. The linkage is developed in the USA as mentioned reasons existence. Also, the USA, unlike Germany, shows big differences in investors contributions into the radical innovations. Capital market institutions support young entrepreneurs for their risky investments with high returns. There is a flexible and effective research stimulation system which takes its focus point as high-tech industry ${ }^{10}$ (Blattel-Mink, 1995:15). Since risky loans are usually short-term with high profit, it restrains the long-term technological advances, thus it does not seem to suit for process innovations (Keck, 1993:137-138).

\footnotetext{
${ }^{9}$ In this case, it is observed that the American economy is deprived of a lack of experienced labour force. Therefore, radical innovation seems hard to apply for some countries.

${ }^{10}$ It is claimed that one of the reasons of support for new investments in the USA is seemed as American leadership. Also, these support are raised due to "anti-cartel law".
} 
As it is mentioned before, the USA has no structural restriction or regulations on the markets, thus the markets are not regulated. Standards are emerged from the results of competition. This structure of the USA system provides an equal specialization on each high-tech needed field (Soskice, 1997). Competition fact in the USA national innovation system prevent to occur a cellular strategy system like in Germany. Furthermore, it has a weak coordination strategy in the education system too. Labour market is mostly work by itself and labour has relatively not much power in the country (Blattel-Mink, 1995:61). Comparison the USA with Germany could give us a table as follows;

\begin{tabular}{cc}
\hline THE USA & GERMANY \\
\hline $\begin{array}{c}\text { Leader of Radical Innovations } \\
\text { Flexible Institutions } \\
\text { Individuality, Flexible Workforce } \\
\text { Donations }\end{array}$ & Leader of Process Innovations \\
Encourage Risky Investments & Strict Institutions \\
Export of Radical Technology & Team Work, Strict Workforce \\
State-Supported & No Donations \\
Foreign Scientists Works Freely & Loan with Fixed Interests \\
Enions and Foundations Are Not Significant & Private Sector \\
There Is No Capital Intensity & Foreign Scientists Cannot Apply What They Know \\
\end{tabular}

Also, capital intensity happened stronger in Germany than it is in the USA because wage-interest relationship increased more in Germany (Blattel-Wink, 1995: 15).

\section{CONCLUSION}

The USA is a leader for radical technological innovations for years because of the flexible institutions. Schumpeter's creative destruction well worked in the USA owe to these institutions and make the USA leader of radical innovations. Labour force, financial system, education institutions are designed for this purpose. As Hübner's opinion "It is not wrong to assume that there is a conservatism behind national technological innovations, which reflects the interests of specific actors. As a result, innovation is not taking place" (Hübner and Nill, 2001:31).

Innovations depend on releasing new products obtained as a result of research and development project on new markets. Germany sleep through the progress of radical innovations during 1980s. Thus, it can be said that the weakness of German industry in terms of radical innovation begun in 1980s. I would like to name it as structural conservatism.

Germany, which is on the line of process innovations, has realized its development thanks to its ingrained industry that provides high-values. That situation is criticized more and more. Besides structural characteristics such as over bureaucracy and rigidity, deformation of political, social and economic structures bring unaffordable costs that is impossible to meet by productivity increase. Germany, because of its innovation structure, as it is mentioned, might be even in trouble with reach of high-technology in long term.

Entrepreneurs are strongly depended on their traditional concepts and production style. Leader sectors of German economy have trouble with the integration of new product and technology. It is still debatable whether Germany provide enough flexibility in institutions in order to be a leader in radical innovations although it has started to take measures since 2007. However, still it is neither easy to get a substantial amount of loan from a bank if you are not the owner of Golf nor benefitted from foreign scientist effectively in Germany. That is to say, even if Germany give hundreds Green Cards away, it seems like they would not compose somewhere such Silicon Valley.

\section{REFERENCES}


Backhaus, A. (1999). Öffentliche Forschungseinrichtungen in regionalen Innovationssystemen. Verflechtung und Wissenstransfer Empirische Ergebnisse aus der Region Südostniedersachsen. In: Hannoversche Geographische Arbeiten 55.

Blattel-Mink, B. (1995). Nationale Inovationssysteme Vergleichende Fallstudie, Stuttgart.

Conrad, K. (1985) Produktivtatslücken nach Wirtschaftszweigen im Internatıonalen Vergleich.Studies in Contemporary Economics, Vol.17. Berlin.

Erber, G. (1998). Discussion Paper No. 159 Prinzipien moderner Technologiepolitik von Georg Erber Berlin, Januar 1998 JEL-Classification: O38 Deutsches Institut fürWirtschaftsforschung Königin-Luise-Str. 5 D-14191 Berlin.

Erlangen, R. J. (2002) Endogenes Geld Inovatıonsfinanzierung in inputlosen System. Uni Marburg.

Gowdy, J. M. (1992). Higher selection processes in evolutionary economic change, Journal of Evolutionary Economics, Vol. 2, No. 1, 1992: 116 .

Haga K. and J. Röpke. (2007). Neukombination (in) der Wissensgesellschaft. Marburg

Herrmann-Pillath, C. (2007). Wissenschaft und Kultur als Kräfte gesellschaftlicher Ordnung während der Transformation", Carsten Herrmann-Pillath, Otto Schlecht und Horst-Friedrich.

Hübner, K. \& J. Nill. (2001). Nachhaltqkait als Inovationsmotor, Berlin.

Keck, O. (1993). The National System for Technical Innovation in Germany, In Nelson R., National Inovation Systems, Oxford.

Krelle, R. (1985). Theorıe des wirtschaftlichen Wachstums. Berlin.

Musiolik, J. (WS 2001/2002). Innovationstheoretische Ansätze in die Wirtschaftsgeographie-Konzepte und Bewertung Nationaler und Regionaler Innovationssysteme Philipps- Universität Marburg.

Neumann, M. (1985). Redistributive Income Taxation and Productivity Growth. Unveröffentliche Manuskript. Nürnberg.

Priddat, B. P (1994). Die Zeit der Institutionen. Elemente einer Theorie der Institutionen in der Ökonomie, Diskussionspapier Nr. 6, Juli 1994, Universität Witten/Herdecke.

Ritter, W. (1993). Allgemeine Wirtschaftsgeographie, München.

Schatzel, L. (1996). Wirtschaftsgeographie 1 Theorie, Paderborn.

Schumpeter, J. (1935). Theorie der wirtschaftlichen Entwicklung, 4.Auflage, Leibzig.

Soskice, D. (1994). Innovation Strategies of Companies: A Comparative Institutional Approach of Some Cross-Country Differences. In: Zapf, W \& Dierkes, M. (Hg.): Institutionenvergleich und Institutionendynamik. Berlin.

Soskice, D. (1997). Technologiepolitik Inovation und nationale Institutionengefüge in Deutschland in FfiederNaschold/David, Soskice/Bob, Hancke/Ulrich/Jürgens(Hrsg), Ökonomische Leistungsfahigkeit und institutionelle Inovation, Berlin.

Wissenschaftliche Beirat Beim Bundeswirtschaftsminiserium. (1985). Steuerpolitik unter gesamtwirtschaftlichen Gesichtspunkten 